\title{
MODEL SUPERVISI KEPERAWATAN TERHADAP PELAKSANAAN SASARAN KESELAMATAN PASIEN DI RUANG RAWAT INAP RSUD POSO
}

\author{
Burhanuddin Basri \\ STIKes Husada Mandiri Poso \\ burhanganteng720@gmail.com
}

\begin{abstract}
Abstrak
Perawat adalah salah satu profesi yang berisiko sangat tinggi dan harus mampu belajar dari insiden dan menindak lanjuti insiden serta implementasi solusi untuk mengurangi dan meminimalkan timbulnya risiko bahaya keselamatan pasien. Supervisi klinis model reflektif interaktif bertujuan untuk mengarahkan individu mencapai tujuan rumah sakit yaitu penangan sasaran keselamatan pasien dengan baik. Oleh sebab itu para supervisor harus memiliki keterampilan membimbing untuk meminimalisir masalah keselamatan pasien di RSUD Poso. Jenis penelitian ini adalah penelitian quasi eksperiment dengan rancangan Pretest Posttest With Control Group Design. Sampel penelitian ini adalah adalah perawat di Ruang Rawat Inap di RSUD Poso 24 orang pada masing-masing kelompok. Analisa data dilakukan dengan menggunakan Chi Square, Independent Sample T Test, Paired Sample t-test, Korelasi Pearson, dan untuk analisis multivariat menggunakan General Linear Model Repeated Measure (GLM-RM). Berdasarkan hasil penelitian dapat disimpulkan bahwa ada perbedaan yang signifikan pelaksanaan sasaran keselamatan pasien sesudah diberlakukan supervisi reflektif interaktif $(0,000)$, pada kelompok intervensi \& kelompok kontrol di Ruang Rawat Inap Kelas 3 RSUD Poso Jakarta. Rata-rata pencapaian skor pelaksanaan sasaran keselamatan pasien antar kelompok menunjukan perbedaan yang signifikan. Pada kelompok intevensi pencapaian skor pelaksanaan sasaran keselamatan pasien lebih maksimum dibandingkan dengan kelompok kontrol. Pada kelompok intervensi pencapaian skor mulai menunjukan peningkatan mulai dari pengukuran ke 2 dan skor maksimum terlihat pada pengukuran ke 5 . Sedangkan pencapaian skor maksimum pada kelompok kontrol tampak maksimum pada pengukuran ke 4 dan cenderung mengalami penurunan skor pada pengukuran berikutnya.
\end{abstract}

Kata Kunci : Supervisi, Reflektif, Interaktif, Keselamatan Pasien, Patient Safety

\section{Pendahuluan}

WHO Collaborating Center for Patient Safety pada tanggal 2 Mei 2007 resmi menerbitkan "Nine Life Saving Patient Safety Solution". Panduan ini mulai disusun sejak tahun 2005 oleh pakar keselamatan pasien di lebih 100 negara dengan mengidentifikasi dan mempelajari berbagai masalah keselamatanpasien. Dengan diterbitkannya Nine Life Saving Patient Safety oleh WHO, maka Komite Keselamatan Pasien Rumah Sakit (KKP-
RS) mendorong rumah sakit di Indonesia untuk menerapkan Sembilan Solusi "LifeSaving" Rumah Sakit, langsung atau bertahap sesuai dengan kemampuan dan kondisi RS masing-masing.

Keselamatan Pasien menurut WHO (2009) Adalah pencegahan kesalahan dan efek samping pada pasien berkaitan dengan pelayanan kesehatan, sesuai dengan undang undang no 44 tahun 2009 tetang Rumah Sakit pasal 43 menyatakan," Bahwa rumah sakit wajib menerapkan keselamatan keselamtan pasien yang dilakukan melalui 
JURNAL ILMU KESEHATAN BHAKTI HUSADA:

HeAlth SCIENCES Journal, Vol. 09 No. 02, DeSEMBER 2018 DOI: https://doi.org/10.34305/jikbh.v9i2.67

laporan Keselamatan pasien (patient safety) merupakan suatu sistem di mana rumah sakit membuat layanan kepada pasien lebih aman. Sistem ini meliputi "assesmen risiko, identifikasi, pengelolaan hal yang berhubungan dengan risiko pasien, pelaporan, dan analisis insiden".Petugas kesehatan harus mampu belajar dari insiden dan menindak lanjuti insiden serta implementasi solusi untuk mengurangi dan meminimalkan timbulnya risiko.( Permenkes No 1691 /MENKES/PER/VIII/2011). Menurut Permenkes no 1691 tersebut rumah sakit wajib mengupayakan pemenuhan Sasaran Keselamatan Pasien yang meliputi tercapainya : Ketepatan identifikasi pasien, Peningkatan komunikasi yang efektif, Peningkatan keamanan obat yang perlu diwaspadai, Kepastian tepat-lokasi, tepatprosedur, tepat-pasien operasi, Pengurangan risiko infeksi terkait pelayanan kesehatan, dan Pengurangan risiko pasien jatuh. Sasaran keselamatan pasien merupakan salah satu standar yang di nilai dalam akreditasi rumah sakit dan masuk ke dalam kriteria mayor penilaian, sehingga merupakan standar yang sangat menentukan kelulusan penilaian akreditasi rumah sakit.

Komitmen manajemen terhadap sasaran keselamatan pasien harus dapat dibuktikan dengan kebijakan pimpinan, panduan tertulis berupa standar prosedur dan pemenuhan semua sarana dan prasarana untuk menunjang semua pelaksanaan sasaran keselamatan pasien tersebut. Perawat supervisor merupakan peran ganda perawat manajer di pelayanan keperawatan, untuk mengawasi pelayanan keperawatan yang diberikan oleh para perawat pelaksana terutama dalam hal keselamtan dalam bekerja baik untuk petugas maupun untuk pasien yang di layani. Salah satu peran dari manajer keperawatan berfungsi sebagai model peran untuk mempengaruhi perilaku perawat dalam menerapkan sasaran keselamatan pasien di rumah sakit sesuai dengan ketentuan dan standar yang di tetapkan oleh komisi Akreditasi rumah sakit.
Ciptaan disebarluaskan di bawah

Lisensi Creative Commons Atribusi-

NonKomersial-BerbagiSerupa 4.0

Internasional.

Berdasarkan latar belakang tersebut peneliti tertarik untuk meneliti tentang "Model Supervisi Keperawatan Terhadap Pelaksanaan Sasaran Keselamatan Pasien di Ruang Rawat Inap RSUD Poso 2017”.

\section{Tinjauan Teoritis}

Supervisi klinis merupakan peran manajer dalam mengarahkan bawahannya untuk mencapai tujuan organisasi. Supervisi klinis bertujuan untuk mengarahkan individu mencapai tujuan dan strategi organisasi, membimbing staf dan mendukung tercapainya kerja klinis yang optimal. Oleh sebab itu para supervisor harus memiliki keterampilan memimpin untuk menyelesaikan masalah sehingga dapat mencapai keberhasilan di tempat bekerja (Sirola-Karvinen \& Hykas, 2008). Supervisi klinis merupakan kekuatan utama dari kerangka kerja klinis di pelayanan (White \& Winstanley, 2010).

Supervisi klinis bukan alat manajemen, tetapi dapat digunakan sebagai dukungan dan dasar untuk praktik profesional yang kreatif. Supervisi klinis penting untuk kerangka kerja dari pengelolaan klinis keperawatan karena untuk pengembangan secara progresif dan kesempatan untuk memperbaiki pelayanan secara terus menerus. Supervisi klinis dipandang sebagai alat untuk pelatihan profesional dan pengembangan untuk memperoleh keterampilan dan pendapat lain mengatakan bahwas upervisi merupakan metode untuk mengembangkan profesionalisme dan keterampilan profesional untuk berlatih (White \& Winstanley, 2010).

Supervisi model reflektif bertujuan agar perawat yang disupervisi dapat memberikan input untuk meningkatkan pelayanan keperawatan lebih baik kedepannya dan juga dapat menyelaraskan antara pendidikan keperawatan dengan praktik keperawatan di lapangan. Sementara pendapat lain menyatakan dapat mengembangkan dan memperluas dan meningkatkan pengetahuan dan 
JURNAL ILMU KESEHATAN BHAKTI HUSADA:

HeAlth SCIENCES Journal, Vol. 09 No. 02, DeSEMBER 2018 DOI: https://doi.org/10.34305/jikbh.v9i2.67

keterampilan klinis perawat melalui pendekatan reflektif didunia pendidikan keperawatan (White \& Winstanley, 2010). Sedangkan Supervisi model interaktif memberikan dampak positif terhadap peningkatan mutu pelayanan keperawatan. Supervisi model interaktif dapat peningkatan keterampilan, peningkatan standar pelayanan keperawatan dan memberikan dukungan untuk perawat dalam memberikan asuhan keperawatan untuk menghadapi masalah - masalah yang terjadi. Supervisi model interaktif merupakan model supervisi yang digunakan dengan tujuan untuk mencapai hal -hal yang telah ditetapkan secara professional dan banyak diterapkan dalam pelayanan keperawatan (Brunero \& Stein-Painbury, 2008).

Supervisi model reflektif interaktif merupakan gabungan antara supervisi model reflektif dan interaktif dalam melakukan peran pengarahan oleh supervisor. Penelitian Rusmegawati (2011) terbukti bahwa dengan supervisi model reflektif interaktif dapat meningkatkan kemampuan perawat pelaksana berfikir kritis menjadi lebih baik setelah dilakukan supervisi model tersebut Pendidikan dan pelatihan penting untuk supervisor keperawatan untuk perkembangan profesional dan frekuensi pelatihan yang harus dilaksanakan secara berkelanjutan. Supervisi yang efektif melibatkan keterampilan dari kompetensi yang didapat dari pendidikan dan pelatihan. Tujuan pelatihan dari supervisi klinis untuk untuk mengembangkan teori atau pengetahuan yang relevan dengan fungsi pengarahan, untuk mengembangkan dan memperbaiki keterampilan supervisor, untuk mengintegrasikan pengembangan teori dan keterampilan serta meningkatkan identitas profesional supervisor.

\section{Metode Penelitian}

Desain penelitian ini adalah kuasi eksperimen dengan rancangan "PretestPosttest With Control Group Design" yaitu rancangan sebelum dimulai perlakukan kedua kelompok diberi tes awal atau pretest untuk mengukur kondisi awal (01).Selanjutnya pada kelompok eksperimen diberi perlakuan (X) dan pada kelompok pembanding tidak diberi. Sesudah selesai perlakuan kedua kelompok diberi teslagi sebagai post tes (Arikunto, 2010).

Variabel terikat dalam penelitian ini adalah penerapan sasaran keselamatan pasien pada kelompok intervensi dan kelompok control sedangkan variable bebasnya adalah supervise keperawatan. Populasi pada penelitian ini adalah seluruh perawat pelaksana ruang rawat inap RSUD Poso dengan jumlah 136 perawat. Perhitungan sample pada penelitian eksperimen ini, menggunakan rumus estimasi proporsi yang mengharuskan peneliti mencari proporsi kelompok yang diberi perlakuan supervisi pada penelitian sebelumnya yaitu pada penelitian Yulita (2012) didaptkan proporsi (pi) sebesar 0,852 , dan proporsi (po) sebesar 0,557.

Berdasarkan rumus diatas besar sampel adalah 48 perawat, untuk kepentingan penelitian sampel dibagi menjadi dua kelompok yaitu 24 orang kelompok intervensi \& 24 orang kelompok kontrol. Pada penelitian ini sampel yang diambil adalah Perawat pelaksana yang bekerja di pelayanan keperawatan minimal 1 tahun, pendidikan minimal DIII Keperawatan, tidak sedang mengikuti tugas belajar atau dinas luar saat penelitian dan tidak sedang cuti kerja.

\section{Hasil Penelitian}

Berdasarkan hasil analisis menunjukkan pada kelompok intervensi lebih banyak yang termasuk dalam usia dewasa awal yaitu sebesar 45,8\%, begitupula pada kelompok kontrol lebih banyak yang termasuk dalam usia dewasa awal yaitu sebesar $66,7 \%$. Untuk variabel jenis kelamin pada kelompok intervensi lebih banyak yang berjenis kelamin perempuan yaitu sebesar $95,8 \%$, begitupula 
JURNAL ILMU KESEHATAN BHAKTI HUSADA:

HeAlth SCIENCES Journal, Vol. 09 No. 02, DeSEMBER 2018

DOI: https://doi.org/10.34305/jikbh.v9i2.67

pada kelompok kontrol lebih banyak yang berjenis kelamin perempuan yaitu sebesar 91,7\%. Untuk variabel jenjang pendidikan pada kelompok intervensi lebih banyak yang pendidikanya jenjang D3 yaitu sebesar $79,2 \%$, begitupula pada kelompok kontrol lebih banyak yang pendidikanya jenjang D3
Ciptaan disebarluaskan di bawah

Lisensi Creative Commons Atribusi-

NonKomersial-BerbagiSerupa 4.0

Internasional.

yaitu sebesar 54,2\%. Untuk variabel lama kerja pada kelompok intervensi lebih banyak yang masa kerja nya 5-10 tahun yaitu sebesar 45,8\%, sedangkan pada kelompok kontrol lebih banyak yang masa kerja nya $<5$ tahun yaitu sebesar $75 \%$. Hasil distribusinya terdapat pada tabel 1

Tabel 1. Distribusi responden berdasarkan karakteristik, Distribusi Frekuensi Karakteristik Responden, di RSUD Poso $(n=24)$

\begin{tabular}{|c|c|c|c|c|}
\hline \multirow[b]{2}{*}{ Variabel } & \multicolumn{2}{|c|}{ Kelompok Intervensi } & \multicolumn{2}{|c|}{ Kelompok Kontrol } \\
\hline & $\begin{array}{c}\text { Frekuensi } \\
\text { (orang) }\end{array}$ & $\begin{array}{c}\text { Persentase } \\
(\%)\end{array}$ & $\begin{array}{c}\text { Frekuensi } \\
\text { (orang) }\end{array}$ & $\begin{array}{c}\text { Persentase } \\
(\%)\end{array}$ \\
\hline \multicolumn{5}{|l|}{ 1. Usia } \\
\hline Lansia awal & 1 & 4,2 & - & - \\
\hline Dewasa akhir & 8 & 33,3 & - & - \\
\hline Dewasa awal & 11 & 45,8 & 16 & 66,7 \\
\hline Remaja akhir & 4 & 16,7 & 8 & 33,3 \\
\hline \multicolumn{5}{|l|}{ 2. Jenis kelamin } \\
\hline Perempuan & 23 & 95,8 & 21 & 91,7 \\
\hline Laki-laki & 1 & 4,2 & 2 & 8,3 \\
\hline \multicolumn{5}{|c|}{ 3. Jenjang pendidikan } \\
\hline D3 & 19 & 79,2 & 13 & 54,2 \\
\hline $\begin{array}{l}\text { S1 } \\
\text { Nerc }\end{array}$ & 5 & 20,8 & 2 & 8,3 \\
\hline Ners & - & - & 9 & 37,5 \\
\hline \multicolumn{5}{|l|}{ 4. Lama Kerja } \\
\hline$<5$ tahun & 3 & 12,5 & 18 & 75 \\
\hline $5-10$ tahun & 11 & 45,8 & 5 & 20,8 \\
\hline$>10$ tahun & 10 & 41,7 & 1 & 4,2 \\
\hline
\end{tabular}

Berdasarkan hasil analisis tampak hasil uji statistik didapatkan bahwa Sig $0,000<0,05$ maka H0 ditolak, dan kesimpulanya adalah ada perbedaan yang signifikan pelaksanaan sasaran keselamatan pasien sesudah diberlakukan supervisi reflektif interaktif, pada kelompok intervensi \& kelompok kontrol. Hasil analisisnya dapat dilihat di tabel 2 .

Tabel 3. Uji Beda Rata-Rata Pelaksanaan Sasaran Keselamatan Pasien, Sesudah Intervensi pada kelompok intervensi \& kelompok kontrol.

\begin{tabular}{cccc}
\hline Kelompok & $\mathrm{N}$ & Rerata & Pvalue \\
\hline Eksperimen & 24 & 32,33 & \multirow{2}{*}{0,000} \\
Kontrol & 24 & 25,04 & \\
\hline
\end{tabular}

Hasil analisis multivariat menunjukan adanya perbedaan nilai skor pelaksanaan sasaran keselamatan pasien antar pengukuran, dan terdapat perbedaan pada interaksi antara skor pengukuran dan kelompok dengan nilai $\mathrm{p}=0,000(\mathrm{p}<0,05)$. Untuk lebih jelas perbedaan pengukuran mana yang berbeda, dapat dilihat pada tabel 3 berikut ini:

Tabel 3. Test of Within-Subject Contrast 


\begin{tabular}{|c|c|c|c|c|c|c|c|}
\hline Source & Keselamatan_pasien & $\begin{array}{c}\text { Type III Sum } \\
\text { of Squares }\end{array}$ & $d f$ & $\begin{array}{l}\text { Mean } \\
\text { Square }\end{array}$ & $F$ & Sig. & $\begin{array}{l}\text { Partial Eta } \\
\text { Squared }\end{array}$ \\
\hline \multirow{4}{*}{$\begin{array}{l}\text { Keselamatan_ } \\
\text { pasien }\end{array}$} & Level 2 vs. Level 1 & 238,521 & 1 & 238,521 & 22,100 & 0,000 & 0,325 \\
\hline & Level 3 vs. Level 1 & 481,333 & 1 & 481,333 & 25,548 & 0,000 & 0,357 \\
\hline & Level 4 vs. Level 1 & 1150,521 & 1 & 1150,521 & 65,911 & 0,000 & 0,589 \\
\hline & Level 5 vs. Level 1 & 816,750 & 1 & 816,750 & 40,697 & 0,000 & 0,469 \\
\hline \multirow{4}{*}{$\begin{array}{l}\text { Keselamatan_ } \\
\text { pasien * } \\
\text { Kelompok }\end{array}$} & Level 2 vs. Level 1 & 6,021 & 1 & 6,021 &, 558 & 0,459 & 0,012 \\
\hline & Level 3 vs. Level 1 & 192,000 & 1 & 192,000 & 10,191 & 0,003 & 0,181 \\
\hline & Level 4 vs. Level 1 & 143,521 & 1 & 143,521 & 8,222 & 0,006 & 0,152 \\
\hline & Level 5 vs. Level 1 & 444,083 & 1 & 444,083 & 22,128 & 0,000 & 0,325 \\
\hline \multirow{4}{*}{$\begin{array}{l}\text { Error(Kesela } \\
\text { matan_pasien } \\
\text { ) }\end{array}$} & Level 2 vs. Level 1 & 496,458 & 46 & 10,793 & & & \\
\hline & Level 3 vs. Level 1 & 866,667 & 46 & 18,841 & & & \\
\hline & Level 4 vs. Level 1 & 802,958 & 46 & 17,456 & & & \\
\hline & Level 5 vs. Level 1 & 923,167 & 46 & 20,069 & & & \\
\hline
\end{tabular}

Hasil uji Within-Subject Contrast menunjukan perbedaan rata-rata pencapaian skor pelaksanaan sasaran keselamatan pasien oleh perawat antara pengukuran 2, 3, 4, dan 5 terhadap pengukuran 1. Pada Pengukuran *Kelompok menunjukan perbedaan rata-rata selisih pencapaian skor pelaksanaan sasaran keselamatan pasien antar pengukuran 3, 4, dan 5 di kedua kelas pembeda. Perbedaan mulai terlihat di pengukuran ke 3 dan nilai Partial Eta Squared terbesar terlihat di pengukuran ke 5 $(0,325)$ sehingga pengukuran ke 5 tersebut merupakan waktu yang optimal dalam pelaksanaan sasaran keselamatan pasien

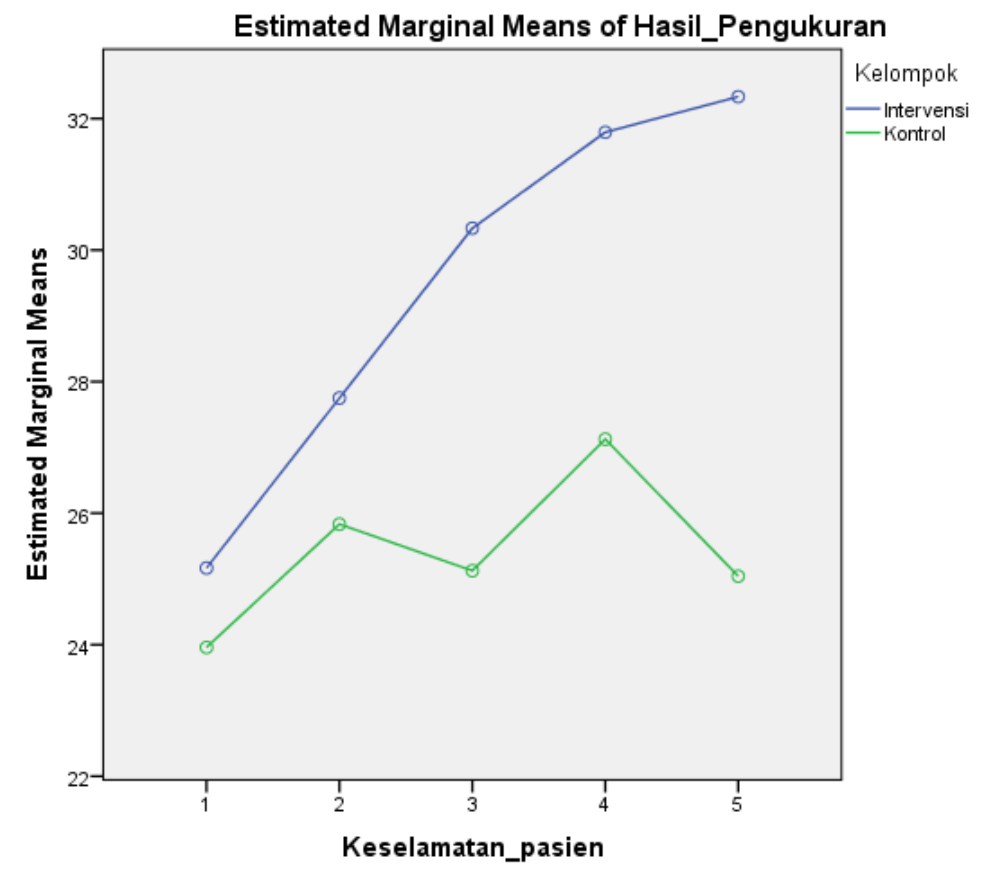

Skema 1

Gambaran kenaikan rata-rata pencapaian skor pelaksanaan sasaran keselamatan pasien pada kenaikan rata-rata tiap pengukuran antar kelompok

Grafik rata-rata pencapaian skor pelaksanaan sasaran keselamatan pasien antar kelompok menunjukan perbedaan yang signifikan. Pada kelompok intevensi pencapaian skor pelaksanaan sasaran keselamatan pasien lebih maksimum dibandingkan dengan kelompok kontrol. Pada kelompok intervensi pencapaian skor 
JURNAL ILMU KESEHATAN BHAKTI HUSADA:

HeAlth SCIENCES Journal, Vol. 09 No. 02, DeSEMBER 2018 DOI: https://doi.org/10.34305/jikbh.v9i2.67

mulai menunjukan peningkatan mulai dari pengukuran ke 2 dan skor maksimum terlihat pada pengukuran ke 5. Sedangkan pencapaian skor maksimum pada kelompok kontrol tampak maksimum pada pengukuran ke 4 dan cenderung mengalami penurunan skor pada pengukuran berikutnya.

Hasil tersebut memperlihatkan bahwa supervisi model reflektif interaktif yang dilakukan di rumah sakit sangat potensial dalam pencapaian pelaksanaan sasaran keselamatan pasien dengan waktu yang lebih singkat dibandingkan dengan rumah sakit yang belum menerapkan model supervisi tersebut.

\section{Pembahasan}

Perbandingan keterampilan berpikir kritis perawat antara kelompok intervensi yang diberikan supervisi reflektif interaktif menunjukkan hasil adanya perbedaan bila dibandingkan dengan kelompok kontrol yang tidak mendapatkan supervisi. Grafik rata-rata pencapaian skor pelaksanaan sasaran keselamatan pasien antar kelompok menunjukan perbedaan yang signifikan. Pada kelompok intevensi pencapaian skor pelaksanaan sasaran keselamatan pasien lebih maksimum dibandingkan dengan kelompok kontrol. Pada kelompok intervensi pencapaian skor mulai menunjukan peningkatan mulai dari pengukuran ke 2 dan skor maksimum terlihat pada pengukuran ke 5. Sedangkan pencapaian skor maksimum pada kelompok kontrol tampak maksimum pada pengukuran ke 4 dan cenderung mengalami penurunan skor pada pengukuran berikutnya.

Hasil yang menunjukkan ada perbedaan bermakna pada pelaksanaan sasaran keselamatan pasien setelah dilakukan supervisi reflektif interaktif pada kelompok intervensi, yang berarti menggambarkan pengaruh supervisi yang menjadi intervensi menjadi alasan terjadi peningkatan keterampilan berpikir kritis perawat, walaupun pada analisis korelasi dinyatakan tidak ada hubungan supervisi dengan pelaksanaan sasaran keselamatan pasien pada kedua kelompok.

Adanya kemajuan pelaksanaan sasaran keselamatan pasien pada kelompok intervensi mungkin disebabkan faktor motivasi perawat itu sendiri. Sebagaimana kita kita ketahui Salah satu amanah dalam UU RS adalah tentang keselamatan pasien atau safety pasien (PerMenKes No. 1691), dan RSUD Poso jelang akreditasi, jadi penelitian ini sangat sesuai dengan fokus rumah sakit dalam meningkatkan layanan keselamatan pasien.

Faktor motivasi, perubahan perilaku kurang baik menjadi baik dapat dapat dipengaruhi oleh motivasi seseorang. Motivasi merupakan karakteristik psikologis manusia yang memberikan konstribusi pada tingkat komitmen seseorang (Suarli \& Bahtiar, 2012). Pernyataan ini dapat didukung oleh hasil penelitian bahwa perubahan perilaku seseorang dipengaruhi oleh motivasi (Jensen, Cushing, Aylward \& Craig, 2011). Faktor motivasi pada kelompok intervensi dan kontrol merupakan faktor yang ikut berpengaruh dalam perawat berperilaku. Pada penelitian ini motivasi berupa dukungan pada perawat pelaksana dengan memberikan reinforcemen positif apabila telah melakukan kegiatan keselamatan perawat yang sesuai dengan standar yang ada dengan demikian dengan adanya motivasi diberikan oleh supervisor dapat terlihat dari hasil penelitian meningkatkan proporsi perawat dalam menerapkan pelaksanaan sasaran keselamatan pasien pada kelompok intervensi.

Faktor tingkat kepatuhan perawat dalam menerapkan pelaksanaan sasaran keselamatan pasien bisa saja dipengaruhi oleh pelatihan yang diperoleh. (Lee, 2010).

Hal yang sama juga disampaikan dalam penelitian lain bahwa tingkat kepatuhan perawat dapat dipengaruhi oleh tingkat pendidikan, pengalaman dan pelatihan tentang infeksi (Lee, 2010). Penelitian oleh Cardoso \& De Figueiredo (2010) pada perawat di rumah sakit di Negara Brazil menyatakan bahwa tingkat 
JURNAL ILMU KESEHATAN BHAKTI HUSADA:

HeAlth SCIENCES Journal, Vol. 09 No. 02, DeSEMBER 2018 DOI: https://doi.org/10.34305/jikbh.v9i2.67

rata-rata kepatuhan terhadap tindakan pencegahan standar adalah: $27,9 \%$ mencuci tangan sebelum prosedur, 41,4\% penggunaan sarung tangan, pembuangan yang tepat $88,8 \%$ dari instrumen benda tajam. Dengan adanya supervisi reflektif interaktif dalam hal ini normatif dapat menjalan kegiatan sesuai dengan standar yang ada dan patuh terhadap standar tersebut sehingga dapat dibandingkan antara kelompok intervensi yang mendapatkan supervisi reflektif interaktif dengan kelompok kontrol yang tidak mendapatkan perlakuan ada perbedaan proporsi perubahan perilaku perawat dalam menerapkan pelaksanaan sasaran keselamatan pasien.

Faktor standar prosedur dan kebijakan, sesuai dengan hasil penelitian bahwa tingkat kepatuhan perawat dalam bekerja dipengaruhi oleh prosedur yang ada. (Darawad, Al-Hussami, Almhairat \& Al-Sutari, 2012). Sehingga dengan standar prosedur yang ada merupakan awal dari perubahan seseorang menjadi berperilaku baik. Kebijakan merupakan awal dari suatu kegiatan dimulai sehingga supervisi klinis dapat dilaksanakan untuk pengarahan klinis pada praktik pelayanan keperawatan yang berbasis bukti (Hill \& Turner, 2011). Standar prosedur dan kebijakan pada kelompok intervensi dan kontrol juga dapat dikontrol seorang manajer dalam melakukan fungsi pengarahan yaitu supervisi. Pada kelompok intervensi tampak bahwa supervisi reflektif terkait dengan adminstrasi dapat mengendalikan perubahan perilaku perawat.

Faktor manusia, organisasi, dan lingkungan, perilaku keselamatan yang disebabkan oleh faktor manusia, organisasi dan budaya tempat kerja, tingkatan staf dan skill mix, harapan pasien, efektivitas kepemimpinan klinis, komitmen untuk kesehatan dan keselamatan, keterampilan, kompetensi, sikap dan perilaku masingmasing anggota staf (Currie et al, 2011). Lingkungan yang sehat bagi perawat merupakan faktor pendukung untuk keselamatan perawat berupa kebijakan organisasi, kebijakan dari profesi keperawatan, psikososial, kognitif, dan budaya (RNAO, 2008). Pada kelompok intervensi maupun kontrol peneliti belum mengontrol sampai pada jam kerja, lingkungan dan budaya organisasi pada kelompok intervensi sehingga dapat dilihat bahawa perbedaan perilaku keselamatan disebabkan oleh faktor-faktor tersebut. Faktor budaya keselamatan, keselamatan perawat harus dibudayakan supaya dijadikan kebiasaan dalam mengubah perilaku. Budaya keselamatan merupakan sistem yang melibatkan tindakan individu dan organisasi.

Faktor misi rumah sakit, keselamatan pasien juga ditentukan dari misi rumah sakit untuk membudayakan keselamatan pasien dengan cara memberikan pelatihan keselamatan dalam melakukan pelayanan dalam hal ini memberikan pelatihan safety di rumah sakit (Omorogbe, Omuemu, \& Isara, 2011). Dengan adanya pengarahan dari seorang supervisor berupa reflektif interaktif diharapkan asuhan keperawatan oleh perawat pelaksana berdasarkan visi dan misi rumah sakit yang mengacu pada tujuan dan strategi pelayanan keperawatan yang dievaluasi oleh kepala ruang sebagai pemimpin dalam pelayanan keperawatan sehingga memang terlihat bahwa supervisi ini untuk mengarahkan perawat pelaksana dalam melakukan praktik keperawatan yang professional yang aman bagi perawat dan pasien.

\section{Kesimpulan}

Berdasarkan hasil penelitian dapat disimpulkan bahwa jenis kelamin dan pendidikan dinyatakan setara, sedangkan variabel usia dan lama kerja diyatakan tidak setara.Berikutnya ada perbedaan yang signifikan pelaksanaan sasaran keselamatan pasien sebelum \& sesudah diberlakukan supervisi reflektif interaktif, pada kelompok intervensi.Berikutnya tidak ada perbedaan yang signifikan pelaksanaan sasaran keselamatan pasien sebelum \& setelah 
JURNAL ILMU KESEHATAN BHAKTI HUSADA:

HeAlth SCIENCES Journal, Vol. 09 No. 02, DeSEMBER 2018 DOI: https://doi.org/10.34305/jikbh.v9i2.67

diberlakukan intervensi, pada kelompok kontrol.Berikutnya tidak ada perbedaan yang signifikan pelaksanaan sasaran keselamatan pasien sebelum diberlakukan supervisi reflektif interaktif, pada kelompok intervensi \& kelompok kontrol. Berikutnya ada perbedaan yang signifikan pelaksanaan sasaran keselamatan pasien sesudah diberlakukan supervisi reflektif interaktif, pada kelompok intervensi \& kelompok kontrol. Berikutnya ada perbedaan yang signifikan pengetahuan sasaran keselamatan pasien sebelum dan sesudah diberlakukan supervisi reflektif interaktif, pada kelompok intervensi.Berikutnya berdasarkan hasil penelitian dapat disimpulkan bahwa supervisi model reflektif interaktif yang dilakukan di rumah sakit sangat potensial dalam pencapaian pelaksanaan sasaran keselamatan pasien dengan waktu yang lebih singkat dibandingkan dengan rumah sakit yang belum menerapkan model supervisi tersebut.

\section{Saran}

1. Saran Untuk Pengembangan Keilmuan Diharapkan Informasi dan hasil penelitian ini dapat memberikan tambahan bukti ilmiah bagi perkembangan ilmu pengetahuan pada umumnya dan pada perkembangan ilmu keperawatan khususnya manajemen keperawatan yang dikelola oleh organisasi perawat manager indonesia.

2. Saran untuk pengembangan praktisi (guna laksana)

a. Bagi Institusi Rumah Sakit

Supervisi model reflektif interaktif diharapkan mendapatkan dukungan dari manajemen keperawatan, kepala ruang dan pelaksana pelayanan untuk meningkatkan ketrampilan berpikir kritis perawat dalam melaksanakan sasaran keselamataan pasein sebagai dasar meningkatkan mutu pelayanan keperawatan di Ruang Rawat Inap RSUD Poso.

b. Bagi Institusi Pendidikan
Ciptaan disebarluaskan di bawah

Lisensi Creative Commons Atribusi-

NonKomersial-BerbagiSerupa 4.0 Internasional.

Diharapkan memperbanyak sumber reverensi terkait program peningkatan pelaksanaan sasaran keselamatan pasien dalam melaksanakan asuhan keperawatan melalui supervisi, agar mahasiswa lebih terpapar hal tersebut, dan lebih siap ketika menemukan kasus sasaran keselamatan pasien.

c. Bagi Ruang Rawat Inap

Supervisi reflektif interaktif yang diterapkan perawat di Ruang Rawat Inap RSUD Poso diharapkan tetap dilanjutkan dan dievaluasi secara terprogram minimal setiap 6 bulan.

d. Bagi Pasien dan Keluarga

Keterampilan pelaksanaan sasaran keselamatan pasien pada kelompok kontrol diharapkan dapat ditingkatkan melalui penerapan supervisi model reflektif interaktif agar dapat meningkatkan pelayanan terhadap pasien atau keluarga.

e. Bagi Peneliti Selanjutnya

Supervisi model reflektif interaktif diharapkan menjadi salah satu model supervisi yang diteliti dan dikembangkan dalam manajemen pelayanan keperawatan di Ruang Rawat Inap RSUD Poso.

\section{Daftar Referensi}

Brunnerro S., \& Stein Parburry, J. (2008). The Effective of Clinical Supervision in

Nursing: an Evidence Based Literature Review.Australian Journal AdvancedNursing, 25(3), 86-94.

Cardoso \& De Figueiredo (2010). Biological risk in nursing care provided in familyhealth units. Revista Latino-Americana De Enfermagem, 18(3), 368-372.

Currie L et al., (2011). Safety: principle of nursing practice c. nursing standard. Art \& Science. Page 35

Darawad MW, Al-Hussami M, Almhairat II, Al-Sutari M (2012), Investigating jordanian nurses' handwashing 
JURNAL ILMU KESEHATAN BHAKTI HUSADA:

HeALTH SCIENCES JOURNAL, Vol. 09 No. 02, DESEMBER 2018 DOI: https://doi.org/10.34305/jikbh.v9i2.67

beliefs, attitudes, and compliance. Am

Infect Control. 2012 Sep;40(7):643-7. doi: 10.1016/j.ajic.2011.08.018

Jensen, C. D., Cushing, C. C., Aylward, B. S., Craig, J. T., Sorell, D. M., \& Steele, R. G. (2011). Effectiveness of motivational interviewing interventions for adolescent substance use behavior change: A metaanalytic review. Journal of Consulting and Clinical Psychology, 79(4), 433-440. doi: http://dx.doi.org/10.1037/a0023992

Lee, W.-C., Wung, H.-Y., Liao, H.-H., Lo, C.-M., Chang, F.-L., Wang, P.-C., . . . Hou, S.-M. (2010). Hospital safety culture in Taiwan: a nationwide survey using Chinese version Safety Attitude Questionnaire. BMC Health Services Research, 10, 234-234.

Omorogbe, VE. Omuemu V O., Alphonsus R. Isara (2012) Injection safety practices among nursing staff of mission hospitals in Benin City, Nigeria

RNAO, (2008) Workplace Health, Safety and Well-being of the Nurse diunduh pada tanggal 15 September 2012 melalui

http://rnao.ca/bpg/guidelines/workplaceh ealth-safety-and-wellbeing-nurseguideline

Rusmegawati, (2011). Pengaruh Supervisi Reflektif Interaktif pada Berpikir Kritis perawat dalam melaksanakan asuhan keperawatan di IRNA I RS Dr. H.M Ansari Saleh Banjarmasin. Depok Tesis FIK UI.
Sirola-Karniven, P., \& Hyrkas, K. (2008). Administrative clinical supervision as evaluated by the first-line managers in one health care organization distrik.

Jurnal of nursing Management, 16(5), 588-600

Suarli, S., Bahtiar, Y. (2012). Manajemen Keperawatan dengan Pendekatan. Praktis. Jakarta: Erlangga

Turner, J., \& Hill, A. (2011). Implementing clinical supervision (part 2): Using proctor's model to structure the implementation of clinical supervision in a ward setting. Mental Health Nursing (Online)

WHO (2009). Human factors in patient safety review of topics and tools: report

for methods and measures working group of WHO patient safety. WHO/IER/PSP/2009.05.

www.who.int/patientsafetyDiakses pada tanggal 12 Feb 2017

Winstanley, J., \& White, E. (2008). Clinical supervision: Models, measures and best practice. Nurse Researcher, 10(4), 7-38. http:// search.proquest.com/ docview/ $200775851 ?$ accountid $=17242$ Diakses pada tanggal 10Feb 2017

Yulita Yeni (2013). Pengaruh Supervisi Model Reflektif Interaktif Terhadap Perilaku Keselamatan Perawat Pada Bahaya Agen Biologik Di Rsud Provinsi Kepulauan Riau Tanjung Uban. Depok 